Bulletin d'Histoire Contemporaine de

l'Espagne

$50 \mid 2016$

Les intellectuels en Espagne, de la dictature à la démocratie (1939-1986)

\title{
La Segunda República en el cine de ficción: Memoria, imagen e historia
}

Igor Barrenechea Marañón

\section{CpenEdition}

\section{Journals}

Edición electrónica

URL: http://journals.openedition.org/bhce/909

DOI: 10.4000/bhce.909

ISSN: 1968-3723

\section{Editor}

Presses Universitaires de Provence

\section{Edición impresa}

Fecha de publicación: 1 diciembre 2016

Paginación: 272-275

ISSN: 0987-4135

\section{Referencia electrónica}

Igor Barrenechea Marañón, « La Segunda República en el cine de ficción: Memoria, imagen e historia », Bulletin d'Histoire Contemporaine de l'Espagne [En línea], 50 | 2016, Publicado el 09 octubre 2018 consultado el 24 septiembre 2020. URL : http://journals.openedition.org/bhce/909; DOI : https:// doi.org/10.4000/bhce.909 
autonomía (a pesar de los recortes que sufrió el texto final), con repetidas loas a la figura filocatalanista de Azaña, Gracia y Justicia, por su parte, no se cansó de exhibir una postura antiautonomista y anticatalanista. Esta oposición al Estatuto tuvo también el respaldo de otras publicaciones conservadoras, de la mayoría del Partido Socialista, así como de figuras influyentes como Miguel de Unamuno o José Ortega y Gasset.

En resumen, el contraste ideológico entre las revistas satíricas permite configurar una interpretación alternativa de los hechos que tuvieron lugar entre 1931 y 1936 . Las revistas satíricas, a pesar de su intención humorística, contribuyeron sin duda a la confrontación ideológica. El estallido de la guerra civil en 1936 supuso el fin de esta dialéctica gráfica, pero no de la dialéctica discursiva que se prolongó más allá de las propias revistas, desaparecidas en este año. Así, el discurso ideológico de Gracia y Justicia, en su sentido católico (como el que también defendía $D I C$ ), militarista y autoritario triunfó con la dictadura franquista, a partir de 1939.

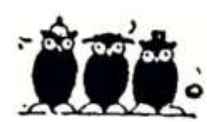

La Segunda República en el cine de ficción: Memoria, imagen e historia ${ }^{1}$

\section{Igor BARRENECHEA MARAÑÓN}

La presente tesis doctoral, dirigida por el catedrático de Historia Contemporánea Santiago de Pablo, es un estudio de cómo ha sido representada y retratada la memoria de la Segunda República española (19311936) por parte de la cinematografía española, centrándose exclusivamente en el cine de ficción y dejando a un lado tanto el cine documental, así como las producciones destinadas a la televisión.

En las últimas décadas, diversos historiadores españoles (Caparrós, Crusells, Hueso, De Pablo) y extranjeros (Rosenstone, Ferro, Sorlin, Sand) han abierto nuevas vías de investigación, desvelando la importancia del cine como fuente histórica y como nueva forma de escribir la Historia, además de profundizar en su influencia en la conformación de mentalidades, de la memoria y del imaginario colectivo. En muy poco tiempo, la relación HistoriaCine se ha convertido en un campo de investigación de enorme interés y en una disciplina de estudio que se ha añadido al currículum universitario.

Sin embargo, todavía hay grandes temas sin estudiar. Es el caso de la visión que el cine ha transmitido del período histórico de la Segunda República española hasta 1936, que (a diferencia del posterior de la Guerra Civil) apenas ha sido abordado, a pesar de ser uno de las etapas claves de la historia de España en el siglo XX. Esta tesis

1 Tesis doctoral defendida el 3 de marzo de 2014 en la Facultad de Letras de la Universidad del País Vasco en Vitoria-Gasteiz. Director: Santiago de Pablo Contreras (U. del País Vasco). Tribunal: Presidente: José Luis de la Granja (U. del País Vasco). Secretaria: Susana Serrano (U. del País Vasco). Vocales: Ángel Luis Hueso (U. de Santiago de Compostela), Amparo Martinez (U. de Zaragoza) y Magi Crusells (Centro de Investigaciones Film-Historia). 
ha buscado llenar ese espacio, del mismo modo que, para otros temas, lo han hecho tesis como las de Sergio Alegre sobre la representación de la División Azul, Magí Crusells sobre las Brigadas Internacionales o la más reciente de Aintzane Rincón sobre las representaciones de género en el cine español (V Premio Artola), entre muchas otras.

Tal y como escribió Manuel Tuñón de Lara, el estudio de la Segunda República tiene una "entidad propia»; no es un anexo o un prólogo de la Guerra Civil, sino que merece ser estudiada por sí misma, tal y como ha hecho la abundante historiografia que ha analizado esos cinco años que abarcan el periodo republicano antes del inicio de la guerra. Ahora bien, si nos preguntamos si el cine ha hecho un esfuerzo similar para reflejar ese periodo, la respuesta es bastante clara: no. Existen pocas películas sobre esta etapa histórica, lo que supone un reto para el investigador y permite inquirir con mayor fuerza acerca de las causas de esa falta de interés, así como de los elementos que sí se han representado en la pantalla.

En buena medida, la representación de la Segunda República en el cine está relacionada con la propia memoria republicana. Así, Josefina Cuesta advierte de la debilidad de esta memoria, que ha sido desplazada o incluso aplastada por el enorme protagonismo de la Guerra Civil. Por otro lado, tal y como señalan Walther $\mathrm{L}$. Bernecker y Sören Brinkamann, el recuerdo de la República ha venido marcado por las altas y exageradas "esperanzas que se depositaron en ella» y en las decepciones consiguientes tras no haber alcanzado sus objetivos de cambio y reforma.

Cada uno de estos tres aspectos (la República como entidad propia, la debilidad de esta memoria y sus frustradas esperanzas) remarcan la perspectiva con que el cine ha enfocado el periodo de 1931-1936.

La metodología aplicada en la tesis parte del marco de análisis establecido por el catedrático José María Caparrós Lera, en línea con los trabajos de Marc Ferro y Robert Rosenstone, estudiando tanto el contexto de la producción como el propio texto filmico y la época histórica reflejada en la pantalla. Por un lado, cada película hay que analizarla en relación al marco histórico en el que se realiza, al ser producida en el marco de una sociedad y estar destinada a ella, como cualquier producto cultural. Por lo tanto, asimila, capta o refleja (o pretende ocultar) una parte de la realidad en la que se ubica, diciéndonos más de esta sociedad presente, en ocasiones, que de aquella a la que hace referencia. Esto influye de forma precisa en el modo (con sus mitos, prejuicios o idealismos) en el que se identifica una sociedad pasada con ciertos valores y realidades inmediatas. Asimismo, ello nos lleva a valorar la recepción de los filmes, las críticas o el número de espectadores en salas comerciales, que es relevante a la hora de calibrar su impacto social, incrementado después por su emisión en televisión o su distribución en vídeo, DVD o Internet.

Por otro lado, en la tesis analizamos el texto fílmico en sí, el modo en el que se establece, como afirma Rosenstone, una nueva relación con el pasado. Conocemos, muchas veces, más de este a través del cine que de los libros de Historia que hayamos podido leer sobre este periodo. La imagen recrea y codifica, así, una ficción con apariencia de realidad que influye en el imaginario colectivo sobre una época; por lo tanto, es esencial extraer los elementos que van a representar y constituir, a la larga, este imaginario, y ahí es donde el cine se convierte en un agente de la Historia. En el cine se representan aspectos de una cotidianidad que pretende desvelar la forma de ser, comportarse y sentir de una determinada sociedad.

Claro que, al analizar el texto fílmico, no podemos ignorar las intenciones de sus creadores. Como todo producto cultural, cada creador tiene su propio propósito 
aunque, en ocasiones, cobre una dirección distinta al enunciado inicialmente. Del mismo modo, puede convertirse en una «historia no oficial» o en un "contraanálisis» de la sociedad, lo que debe servir para preguntarnos por qué lo hace y qué mensaje pretende trasmitir. Por ello, hemos de valorar la inadecuación o adecuación de esta visión sugerida de la recreación de ese registro histórico. Todo ello ayuda a configurar una memoria audiovisual que los historiadores debemos valorar (como hacemos con otros documentos) como fuente histórica para interpretar sus significados.

Sin embargo, el lenguaje del cine es diferente de la historiografia escrita; no es una traslación directa de la Historia en imágenes, sino que utiliza sus propias técnicas narrativas, influyendo enormemente esos otros factores ambientales que crean el discurso fímico, como son el montaje, la luz, la fotografia, la música, etc., aquellos aspectos que hacen más o menos veraz o creíble la representación histórica. Además, el cine sostiene, en su complejidad, una singular capacidad de síntesis, elaborando, asimismo, metáforas o simbolismos que hemos de interpretar. Tampoco podemos ignorar esa otra información que nos ofrece y que tiene que ver con el hecho de que el cine, y sus personajes, infieren una carga emocional, que influye y determina la credibilidad o no de los hechos que nos cuentan. Además, no todos los filmes tienen el mismo valor histórico.

Dentro de este marco metodológico, la estructura de la tesis se divide en 15 capítulos. El primero, de carácter introductorio, está compuesto de dos epígrafes. En el primero de ellos se explica el nacimiento, a finales de la década de 1970, de la importancia de la fuente visual en el conocimiento histórico hasta convertir las relaciones de historia y cine en una disciplina académica de reconocido prestigio. En el segundo epígrafe se comenta la metodología (antes expuesta) y el criterio seguido a la hora de elegir los filmes tratados en la tesis (centrados en la Segunda República, descartando otros menos relevantes, por su significado o por dedicar escaso metraje a esta etapa). Por supuesto, esto conlleva una elección subjetiva, estableciendo una serie de criterios que marcan la representatividad de la Segunda República en los filmes o su interés a la hora de proceder a llevar a cabo un retrato lo más acabado posible de este periodo (temáticas, lugares de rodaje, contexto histórico, etc.).

Tras este primer capítulo, en el que se explican los fundamentos principales de la tesis, se desarrolla y describe el contexto histórico en el que se inscriben los filmes, o lo que es lo mismo, una sintética historia de la Segunda República española, hasta su abrupto final, en julio de 1936, dejando a un lado la Guerra Civil española (1936-1939). A continuación, en el capítulo tercero se revisa la evolución de la memoria colectiva sobre la Segunda República desde 1939 a 2004. Y aunque el último filme de análisis está fechado en 2001, he considerado pertinente continuar el estudio tres años más, para que se vislumbre que a partir de ese instante se ha abierto un marco diferente, a raíz de lo que vendrá a ser la aprobación de la llamada Ley de la Memoria Histórica (2007). Este capítulo viene estructurado en tres periodos de tiempo: Franquismo (19391975), Transición (1975-1985) y década de 1990.

A partir de ahí, en cada uno de los siguientes capítulos (del 4 al 12) se analizan, siguiendo un orden cronológico de producción, los nueve filmes que componen esta mirada a la memoria cinematográfica de la República: Fortunato (1941), de Fernando Delgado; Cerca del Cielo (1951), de Domingo Viladomat y Mariano Pombo; Retrato de Familia (1976), de Antonio Giménez; Mi hija Hildegart (1977), de Fernando Fernán Gómez; Tierra de rastrojos (1979), de Antonio Gonzalo; Réquiem por un campesino español (1985), 
de Francesc Betriu; Pasiones rotas (1995), de Nick Hamm; La lengua de las mariposas (1999), de José Luis Cuerda; y Visionarios (2001), de Manuel Gutiérrez Aragón.

La tesis doctoral se completa con las conclusiones, las fuentes y la bibliografia, y un anexo con un catálogo no exhaustivo de otros filmes que hablan o hacen alguna alusión a la etapa republicana, dando pistas $\mathrm{y}$ argumentos complementarios para valorar este conjunto de elementos que componen esta memoria audiovisual republicana.

En suma, los filmes están clasificados en tres etapas fundamentales, adaptando (aunque con matices) las que utiliza el insigne Julio Aróstegui para la Guerra Civil:

$1^{\circ}$ Etapa. Memoria de la justificación del pronunciamiento militar, que coincide con el periodo del franquismo, en la que estarían integrados Fortunato y Cerca del Cielo. En ellos se recogen buena parte de los mitos negativos de la República, como son el caos político, anticlericalismo, desorden y miseria. Si Fortunato es un filme curioso, ya que representa la sociedad franquista, aunque en el marco republicano, Cerca del cielo sintetiza todo el cine de cruzada en el que se enmarca esta visión maniquea y totalmente ideologizada contra la República. El filme encarna, como ningún otro, esta impostada mirada sobre el periodo anterior al fallido golpe militar, con manidos clichés que hablan de la verdadera España (recuperada tras el golpe militar de julio de 1936) frente a una anti-España republicana.

$2^{\circ}$ Etapa. La memoria de la reconciliación se desarrolla durante la Transición, con los filmes Retrato de familia, Mi hija Hildegart, Tierra de rastrojos y Réquiem por un campesino español. Estos filmes trataron de recuperar el pasado como lección del presente. Esto se refleja bastante bien en los dos primeros y algo menos en los dos siguientes, que serían un puente con el cine de la reparación de las víctimas, al tratar, en ambos casos, la represión contra los perdedores de la guerra y establecer un cierto idealismo del periodo republicano y su reformismo agrario. La época republicana se instaura entre dos mundos, uno anterior, arcaico y en cambio, y otro que se verá roto o destruido por la contienda civil.

$3^{\circ}$ Etapa. La memoria de la reparación que surge a partir de la década de los años 90, reflejándose en los filmes Pasiones rotas, La lengua de las mariposas y Visionarios, en los que existe un nexo en común a todos ellos, como es una recreación de un idealismo republicano. Ahora bien, tanto Pasiones rotas como Visionarios cabría considerarlos como unos filmes inadecuados a la hora de reconstruir ese pasado, debido a sus muchas incongruencias, una falta de autenticidad y la utilización de clichés y mitos propios de épocas pasadas (buenos/ malos; fascismo/comunismo; violencia/ Frente Popular). Aquí hay incluso cierta huella de una inequívoca lectura negativa del contexto republicano, dominado por los peligrosos antagonismos y fanatismos.

Frente a estas dos producciones se encuentra La lengua de las mariposas, que encarna, en su belleza poética, un proyecto democratizador de la sociedad española, roto por el fanatismo y el conservadurismo español. Marca el cuadro idealizado del sueño educativo republicano y la abrupta ruptura provocada por la guerra.

En el lado más positivo, el conjunto de los filmes van a tratar muchos de los temas más relevantes de la etapa republicana, como fueron la cuestión agraria, la debilidad política del régimen, la cuestión religiosa, el choque de mentalidades entre tradicionalismo y modernidad, tensiones y violencia política y social, temores ideológicos exagerados (fascismo/comunismo) y la Segunda República vinculada a la inevitabilidad de la Guerra Civil.

De esta manera, podemos concluir que, en general, muchos de los filmes abarcan periodos largos de tiempo, lo que hace que la República sea, en algunos casos, un capítulo más de la historia, o ya fundamentalmente 
la antesala inevitable de la contienda. La República española apenas ha cobrado una entidad propia, reflejando lo pertinente de la citada reivindicación del profesor Tuñón de Lara. En cambio, se lleva a cabo una representación de dos Españas republicanas: una, que lleva la etiqueta negativa de inestabilidad y desorden, comunismo/ fascismo y violencia; y otra idealizadora, reformista, laicista, feminista y democrática, frente al rancio conservadurismo de una España clerical y caciquil.

Estas sensibilidades encontradas se muestran mayormente de forma superficial, manida y falta de una compleja representación, que permite la pervivencia de viejos mitos. Los filmes contribuyen, en suma, a la constitución de una memoria fragmentada, contradictoria, negativa e idealizada del periodo, que impide constituir un simbolismo cinematográfico definido y mejor contextualizado en el imaginario social, lo cual lleva a la pervivencia de mitificaciones (sean positivas o negativas) de la Segunda República por medio del cine.

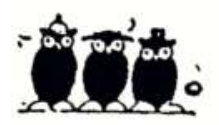

\section{La guerra de Ifni-Sáhara y la lucha por el poder en Marruecos ${ }^{1}$}

\section{Juan PASTRANA PIÑERO}

La tesis propone una revisión de la historiografia existente hasta el momento sobre el último conflicto colonial español. Éste ha sido interpretado, generalmente, como una agresión encubierta del recientemente independizado Reino de

1 Tesis de Historia leída el 5 de abril de 2013, en la Universitat Pompeu Fabra de Barcelona. Director: Dr. Josep Pich i Mitjana. Tribunal: Dr. Eloy Martín Corrales (presidente), Dr. Jesús $\mathrm{M}^{\mathrm{a}}$ Martínez Millán (secretario), Dr. José Antonio Rodriguez Esteban (vocal).
Marruecos contra los últimos vestigios del pasado colonial español. Sin embargo, gran parte de la bibliografía existente proviene de antiguos militares cuya percepción de los hechos viene influenciada por sus vivencias personales.

Por el contrario, la tesis defendida por el Dr. Juan Pastrana Piñero, alejado de dichos condicionantes, aporta nuevas interpretaciones de los hechos sucedidos en la extinta África Occidental Española (A.O.E.) mediante la incorporación de nuevas fuentes de archivo y bibliográficas. Entre las diversas fuentes utilizadas, se encuentran los archivos españoles del Servicio HistóricoMilitar, la Fundación Francisco Franco, el Archivo General de la Administración, el francés del Service Historique de la Défense y los norteamericanos del Department of State y la Central Intelligence Agency. La tesis circunscribe los hechos militares al contexto político del momento, presentando el choque armado como una continuación de los hechos acaecidos en el África Occidental Francesa (A.O.F.) durante 1956 y 1957.

La tesis se encuentra estructurada en cuatro bloques. En el primero de ellos se analizan los orígenes de la presencia europea en el Magreb y el nacimiento del A.O.E., así como su evolución hasta 1956. En este bloque se contraponen los puntos de vista español, francés y marroquí mediante un amplio uso de fuentes bibliográficas procedentes de los tres países implicados en el posterior conflicto, destacando la influencia de hechos como la Conferencia de Algeciras y el choque de intereses coloniales entre España y Francia, así como los acuerdos a que llegaron ambos países europeos para la repartición del Imperio Jerifiano.

El segundo bloque presenta la evolución política marroquí y del A.O.E. durante el período previo al desencadenamiento de las hostilidades, así como la influencia de la política de EE.UU. en la zona. Destaca en este apartado, que reinterpreta la cadena 